\title{
Delta-like 3 is silenced by methylation and induces apoptosis in human hepatocellular carcinoma
}

\author{
KENTARO MAEMURA $^{1}$, HIROHIDE YOSHIKAWA ${ }^{2}$, KAZUTAKE YOKOYAMA ${ }^{1,3}$, TERUO UENO ${ }^{4}$, \\ HITOMI KUROSE $^{1}$, KAZUHISA UCHIYAMA ${ }^{3}$ and YOSHINORI OTSUKI ${ }^{1}$ \\ ${ }^{1}$ Department of Anatomy and Cell Biology, Osaka Medical College, Takatsuki, Osaka; \\ ${ }^{2}$ Department of Internal Medicine, Sassa General Hospital, Nishi-tokyo, Tokyo; \\ ${ }^{3}$ Department of General and Gastroenterological Surgery, ${ }^{4}$ Central Research Unit, \\ Osaka Medical College, Takatsuki, Osaka, Japan
}

Received October 26, 2012; Accepted December 7, 2012

DOI: $10.3892 /$ ijo.2013.1778

\begin{abstract}
The genetic and epigenetic events of hepatocarcinogenesis are relatively poorly understood. By analyzing genes from human hepatocellular carcinoma (HCC) with restriction landmark genomic scanning, several aberrantly methylated genes, including Delta-like 3 (DLL3), have been isolated. In this study, we investigated the function of DLL3 in hepatocarcinogenesis. Methylation of the DLL3 gene in HCC cell lines was investigated with methylation-specific PCR and expression of DLL3 mRNA in HCC cells was examined by RT-PCR. Reactivation of DLL3 expression by treatment with a demethylating agent was examined in methylation-silenced $\mathrm{HuH} 2$ cells. Human DLL3 cDNA was cloned and DLL3 function was examined by restoring DLL3 expression in $\mathrm{HuH} 2$ cells. The effects of DLL3 on cell growth were evaluated by colony formation assay. Induction of cell death by overexpression of DLL3 was examined by flow cytometric assay using Annexin V and PI. Apoptotic cells were detected by TUNEL staining and the amount of single-stranded DNA was measured by ELISA. As a result, the promoter region of the $D L L 3$ gene was methylated in four of ten HCC cell lines. This aberrant methylation correlated well with the suppression of RNA expression and a demethylating agent reactivated DLL3 expression in methylation-silenced HCC cells. Interestingly, the restoration of DLL3 in the methylation-silenced $\mathrm{HuH} 2$ cells led to growth suppression on colony formation assay. Flow cytometric assay with Annexin V and PI showed that this growth suppression by DLL3 expression is associated with the induction of apoptosis. Furthermore, these apoptotic effects were confirmed by TUNEL staining and measurement of single-stranded DNA.
\end{abstract}

Correspondence to: Dr Kentaro Maemura, Department of Anatomy and Cell Biology, Osaka Medical College, 2-7 Daigaku-machi, Takatsuki, Osaka 5698686, Japan

E-mail: an2011@art.osaka-med.ac.jp

Key words: Delta-like 3, hepatocellular carcinoma, methylation, apoptosis
These results suggest that DLL3 was silenced by methylation in human HCC and that it negatively regulates the growth of HCC cells.

\section{Introduction}

Hepatocellular carcinoma (HCC) is one of the most common malignant tumors worldwide and most HCC arises from chronic liver disease, which is associated with liver cirrhosis. Etiological factors for hepatocarcinogenesis include chronic hepatitis $\mathrm{B}$ or hepatitis $\mathrm{C}$ virus infection, long-term exposure to aflatoxin B1 in food, alcohol addiction and hemochromatosis. The precise molecular mechanisms for its development beyond initiation have not been elucidated, but as for many other tumors, the development and progression of HCC is a multistep process and activation of oncogenes and inactivation of tumor suppressor genes caused by genetic or epigenetic aberrance are involved in carcinogenesis (1). Among these, epigenetic inactivation of tumor suppressor genes by hypermethylation of $\mathrm{CpG}$ islands in promoter sequences plays an important role (2-4). Yoshikawa et al (6) compared genomic NotI restriction fragments between normal and HCC tissues by restriction landmark genomic scanning (RLGS) analysis and isolated several aberrantly methylated genes, such as suppressor of cytokine signaling-1 (SOCS-1), SOCS-3 and apoptotic speck protein-like (ASCL) (5-10).

Here, we demonstrate that the Delta-like 3 (DLL3) gene was aberrantly methylated in its $\mathrm{CpG}$ island in $\mathrm{HCC}$ cells. DLL3 is a member of Delta/Serrate/Lag2 (DSL) ligands for Notch receptors and plays a role in Notch signaling. Five DSL ligands (DLL1, 3, 4; and Jagged 1 and 2) and four Notch receptors have been identified in mammals (11). Notch signaling is an evolutionarily conserved signaling pathway essential for embryonic development and regulates cellular processes such as differentiation, proliferation, survival and apoptosis in various cell types $(12,13)$. However, DLL3 is the most structurally divergent DSL ligand and function of DLL3 in Notch signaling is complicated by conflicting reports (14-16). DLL3 is expressed throughout the presomitic mesoderm and is localized to the rostral somatic compartments. Homozygous 
disruptions of Notch1 and DLL3 result in severe abnormalities in somitogenesis (17-19) and mutations in the human DLL3 homolog cause recessive skeletal abnormalities in spondylocostal dysostosis (20-22). The role of DLL3 in carcinogenesis has not been reported.

In this study, we sought to examine the silencing of DLL3 by methylation and to characterize its roles in HCC. Our data indicate that DLL3 is silenced by methylation and DLL3 expression is associated with cell growth suppression in HCC. Our findings confirm a novel function of DLL3 in hepatocarcinogenesis.

\section{Materials and methods}

Cell lines. Human HCC cell lines HuH1, HuH4 and HuH7 were purchased from the Japanese Culture Collection. HuH2 and Kim1 were gifts from the Department of Pathology, The Cancer Institute and the Japanese Foundation for Cancer Research. Hep3B and Li-7 were obtained from the cell resource center for Biomedical Research Institute of Development, Aging and Cancer, Tohoku University. FLC4 was a gift from Dr Seishi Nagamori. Cells were maintained in RPMI-1640 medium (Sigma-Aldrich, St. Louis, MO, USA) containing $10 \%$ fetal bovine serum (Invitrogen, Carlsbad, CA, USA) at $37^{\circ} \mathrm{C}$ under a $5 \% \mathrm{CO}_{2}$ atmosphere. For DLL3-reactivation study, cells were treated with $1 \mu \mathrm{M}$ 5-Aza-2'-deoxycytidine (5-Aza-dC) alone for 4 days or with $1 \mu \mathrm{M}$ 5-Aza-dC for 4 days and $300 \mathrm{nM}$ trichostatin A (TSA) for 1 day.

Reverse transcription-PCR analysis. Total RNA of HCC cell lines was isolated using an RNeasy mini kit (Qiagen, Hilden, Germany), and cDNA was synthesized using the Superscript Preamplification System (Invitrogen). An aliquot of cDNA was subjected to amplification using Taq polymerase (Takara, Shiga, Japan). The primer sequences were CGAGCTGCAGAT CCACTCT and CGCCTCACATTCGTCCTC. The reaction was carried out for 35 cycles of denaturation at $94^{\circ} \mathrm{C}$ for $40 \mathrm{sec}$, annealing at $62^{\circ} \mathrm{C}$ for $40 \mathrm{sec}$ and extension $72^{\circ} \mathrm{C}$ for $180 \mathrm{sec}$. An aliquot of PCR product was analyzed by $1.5 \%$ agarose gel electrophoresis, followed by ethidium bromide staining.

Methylation-specific PCR (MSP). Bisulfite modification of genomic DNA was performed as described previously (23). The methylation-specific primer sequences for $D L L 3$ were CGGGATTATTTACGTATGATTTC [nucleotides (nt) 103,584-103,606 in AC011500] and CCGACCCCAAAAA ACCAAAAACG (nt 103,686-103,708). The unmethylation-specific primer sequences were TGTGGGATTATTTA TGTATGATTTT (nt 103,582-103,606) and CCCAACCCCA AAAAACCAAAAACA (nt 103,686-103,709). An aliquot of bisulfite-modified DNA was amplified by PCR. PCR was carried out with preheating at $94^{\circ} \mathrm{C}$ for $120 \mathrm{sec}$ and $80^{\circ} \mathrm{C}$ for $30 \mathrm{sec}$, followed by $30 \mathrm{cycles}$ of $94^{\circ} \mathrm{C}$ for $40 \mathrm{sec}, 60^{\circ} \mathrm{C}$ for $40 \mathrm{sec}$ and $72^{\circ} \mathrm{C}$ for $60 \mathrm{sec}$. An aliquot of PCR product was analyzed by $4.0 \%$ agarose gel electrophoresis.

Construction of expression vector. A full-length DLL3 cDNA was isolated from human liver RNA (BD Sciences, Rockville, $\mathrm{MD}, \mathrm{USA}$ ) by PCR and the product was cloned into the EcoRI site of a pcDNA 3.1/HisB vector (Invitrogen). A clone, desig- nated pcDNA3-DLL3, showed an in-frame ligation and correct sequence.

Colony formation assay. Cells $\left(5.0 \times 10^{4}\right.$ for $\mathrm{HuH} 2,1.0 \times 10^{5}$ for Kim1) were transfected with $4 \mu \mathrm{g}$ of either pcDNA-DLL3 or pcDNA3.1 backbone vector. Colonies were selected in the presence of G418 (1,000 $\mu \mathrm{g} / \mathrm{ml}$ for HuH2, $300 \mu \mathrm{g} / \mathrm{ml}$ for Kim1) for 4 weeks and colonies were photographed after staining.

Flow cytometry analysis of cell death. $\mathrm{HuH} 2$ cells were transfected with either pcDNA-DLL3 or pcDNA3.1 backbone vector. After $48 \mathrm{~h}$, cell apoptosis was analyzed with an Annexin V-FITC kit (Bender MedSystems, Burlingame, CA, USA) along with PI according to the manufacturer's protocol. Briefly, both adhered and floating cells $\left(5 \times 10^{5} / \mathrm{ml}\right)$ were resuspended in binding buffer and incubated with Annexin V-FITC for $10 \mathrm{~min}$ at room temperature. Cells were then washed with PBS and incubated with PI (final concentration $1 \mu \mathrm{g} / \mathrm{ml}$ ) solution and DNA contents of the cells were measured with a flow cytometer (Beckman Coulter, Brea, CA, USA).

TUNEL analysis. TUNEL assay was performed using a kit (Roche Biochemicals Inc., Mannheim, Germany) according to manufacturer's protocol. Briefly, cells were plated on $18 \times 18 \mathrm{~mm}$ coverslips placed in a 6 -well plate and transfected with $1 \mu \mathrm{g}$ of either pcDNA-DLL3 or pcDNA3.1 backbone vector. After $48 \mathrm{~h}$, cells were fixed with $4 \%$ paraformaldehyde, and permeabilized with $0.1 \%$ Triton X-100 after blocking endogenous peroxidase. TUNEL reaction mixture was added to the cells and cells were incubated with converter-POD before adding substrate solution. Over 3,000 cells were counted from 15 randomly selected fields under a microscope.

Measurement of single-stranded DNA. DNA in apoptotic cells is sensitive to formamide and denatured DNA was detected with a monoclonal antibody against single-stranded DNA with an ApoStrand ${ }^{\mathrm{TM}}$ ELISA apoptosis detection kit (Enzo Life Sciences, Plymouth Meeting, PA, USA) according to the manufacturer's protocol. Briefly, $3.0 \times 10^{3}$ or $4.0 \times 10^{3}$ cells were plated in a 96-well microplate and transfected with $50 \mathrm{ng}$ of either pcDNA-DLL3 or pcDNA3.1 backbone vector. After $48 \mathrm{~h}$, cells were fixed and dried to attach cells to the plate surface. Cells were then treated with formamide and heated at $56^{\circ} \mathrm{C}$ for $30 \mathrm{~min}$ and were then incubated with antibody mixture for $30 \mathrm{~min}$ after blocking non-specific binding sites. After washing, peroxidase substrate was added to each well and absorbance was measured at $405 \mathrm{~nm}$ with an ELISA reader (Corona Electric Co. Ltd., Ibaragi, Japan).

Western blot analysis. Expression of cleaved Notch I was detected by western blot analysis. Cells were seeded onto $10-\mathrm{cm}$ dishes and transfected with $4 \mu \mathrm{g}$ of either pcDNA-DLL3 or pcDNA3.1 backbone vector. After $48 \mathrm{~h}$, cells were solubilized in lysis buffer [20 mM Tris- $\mathrm{HCl} \mathrm{pH} 8.0,150 \mathrm{mM} \mathrm{NaCl}$, $1 \%$ NP-40, $0.5 \%$ deoxycholic acid, $0.1 \%$ sodium dodecyl sulfate containing complete protease inhibitor cocktail (Roche Diagnostic GmbH, Mannheim, Germany)], followed by centrifugation at $14,000 \mathrm{rpm}$ for $15 \mathrm{~min}$ at $4^{\circ} \mathrm{C}$. Supernatants $(20 \mu \mathrm{g})$ were resolved by electrophoresis and were transferred to Immobilon-P membrane (Millipore, Billerica, MA, USA). 
A

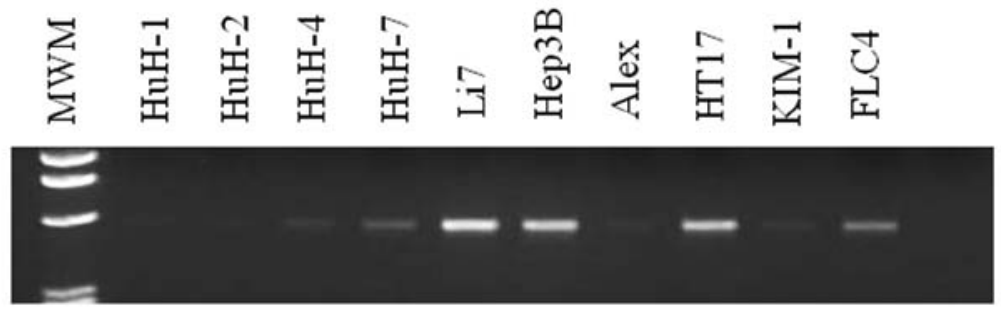

B

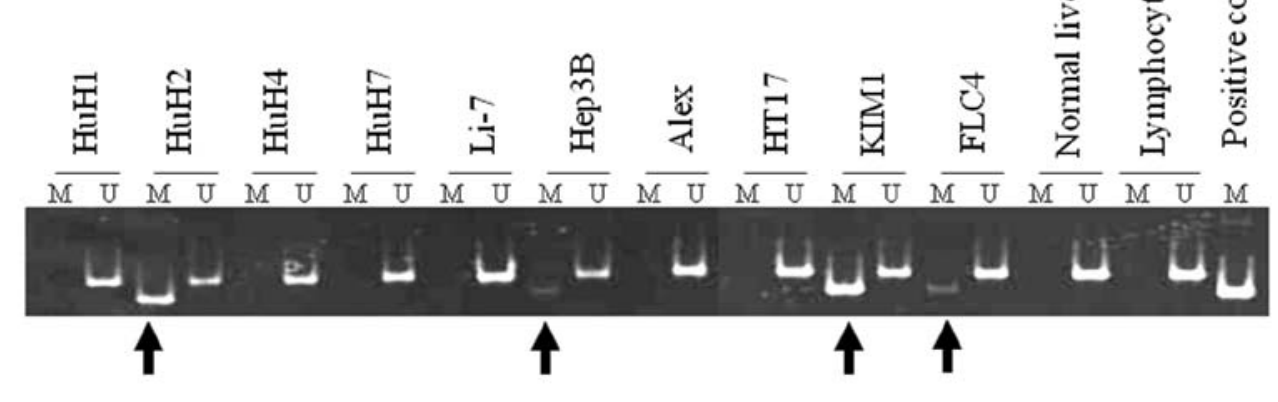

$\mathrm{C}$

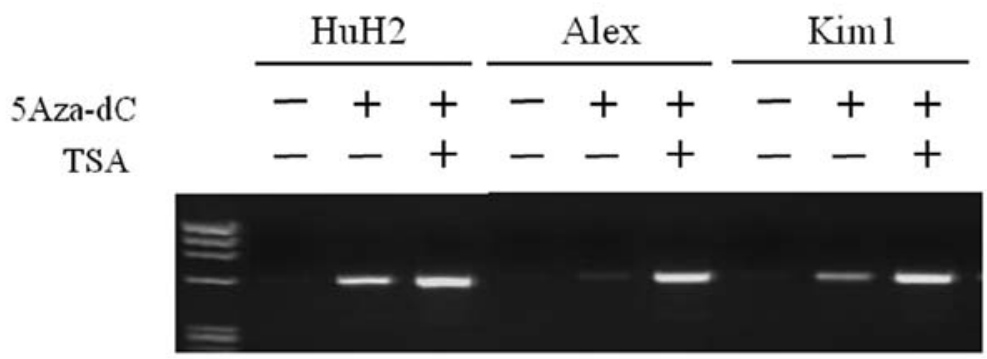

Figure 1. DLL3 mRNA expression and aberrant methylation of DLL3 gene. (A) RT-PCR analysis of DLL3 mRNA from 10 HCC cell lines. No mRNA was detected in HuH1, HuH2, HiuH4, Alex or Kim-1 cells. (B) Methylation of DLL3 was analyzed with MSP using the primer set around the translation start site in $10 \mathrm{HCC}$ cell lines, a non-tumorous liver and lymphocytes. Visible bands in M-lanes (arrows) are methylated PCR products with methylation-specific primers. Visible bands in U-lanes are unmethylated PCR products with unmethylation-specific primers. (C) Three methylated cell lines (HuH2, Alex and Kim1) were treated with or without 5-Aza-2'-deoxycytidine (5-Aza-dC) and DLL3 mRNA expression was analyzed by RT-PCR.

Cleaved Notch was detected by probing membrane with antibody against cleaved Notch (Cell Signaling Technology, Beverly, MA, USA). Horseradish peroxidase-labeled anti-rabbit IgG was used as a secondary antibody and chemiluminescent reaction was carried out using ECL plus western blotting detection reagents (GE Healthcare UK, Buckinghamshire, UK). Signals were detected with a LAS-3000 lumino image analyzer (Fuji Photo Film, Tokyo, Japan).

\section{Results}

mRNA expression and methylation status of DLL3 in HCC cells. We first analyzed DLL3 mRNA expression in $10 \mathrm{HCC}$ cell lines. As shown in Fig. 1A, an amplified band was clearly detected in 6 cell lines (HuH4, HuH7, Li7, Hep3B, HT17 and FLC4) and a faint band was detected in Alex and Kim1 cells. No mRNA expression was observed in $\mathrm{HuH} 1$, $\mathrm{HuH} 2$ cells in addition to normal liver.

Methylation status of the DLL3 CpG islands was then analyzed by MSP. A primer set was designed in exon1, which lies within the DLL3 CpG islands. As shown in Fig. 1B, apparent methylation of $D L L 3$ was detected in four $(\mathrm{HuH} 2$, Hep3B, Kim1 and FLC4) cell lines among 10 cell lines tested with RT-PCR. Aberrant methylation of DLL3 was not detected in normal liver tissue or lymphocytes.
We next analyzed whether a demethylating agent, 5-Aza-2'-deoxycytidine (5-Aza-dC), and a histone deacetylase inhibitor, trichostatin A (TSA), can reactivate DLL3 expression in $\mathrm{HuH} 1, \mathrm{HuH} 2, \mathrm{HuH} 4$, Alex and Kim1 cells. As shown in Fig. 1C, DLL3 expression was reactivated by 5-Aza-dC treatment in all cell lines tested. Although no methylation was detected in HuH1 and Alex cells with MSP, a clear amplified band was detected in these cells after treatment of 5-Aza-dC. Moreover, a robust effect was obtained by additional treatment with TSA in HuH2, Alex and Kim1 cells. These results suggest that expression of DLL3 is frequently suppressed or silenced in association with DNA methylation in HCC cells.

Growth suppression by DLL3 restoration. Colony formation assay was performed in order to investigate the effects of DLL3 overexpression on cell growth. As shown in Fig. 2, overexpression of DLL3 markedly suppressed colony formation in both $\mathrm{HuH} 2$ and Kim1 cells, in which DLL3 was silenced in association with DNA methylation. This suggests that DLL3 has cell growth activity in HCC cells.

Induction of cell death by DLL3 expression. Flow cytometric analysis was performed in order to investigate the effects of DLL3 overexpression on cell death. Of the cells transfected with backbone vector, 21.2 and 18.9\% were positive for PI and Annexin V, 
$\mathrm{HuH} 2$

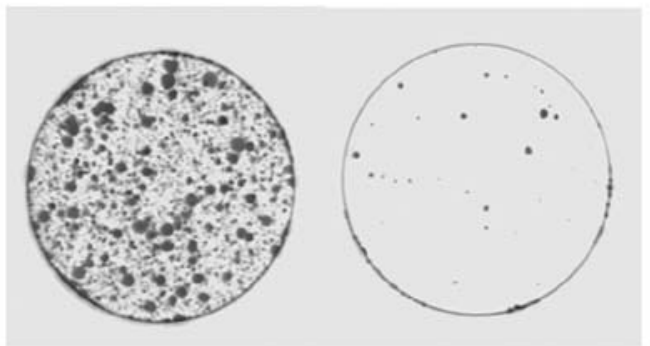

Empty vector

DLL3

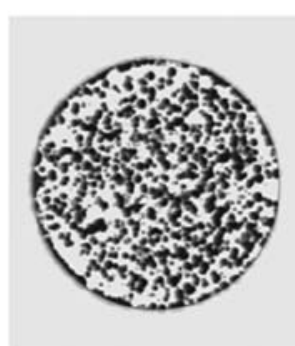

Empty vector
$\operatorname{Kim} 1$

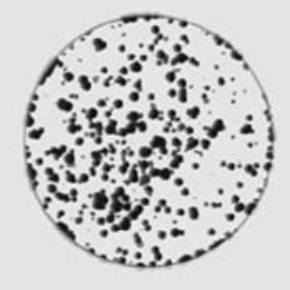

DLL3

Figure 2. Growth suppression by DLL3. Methylation-silenced cells (HuH2 and Kim1) were transfected with either DLL3 expression vector or backbone vector and selected for 4 weeks with G418.

A
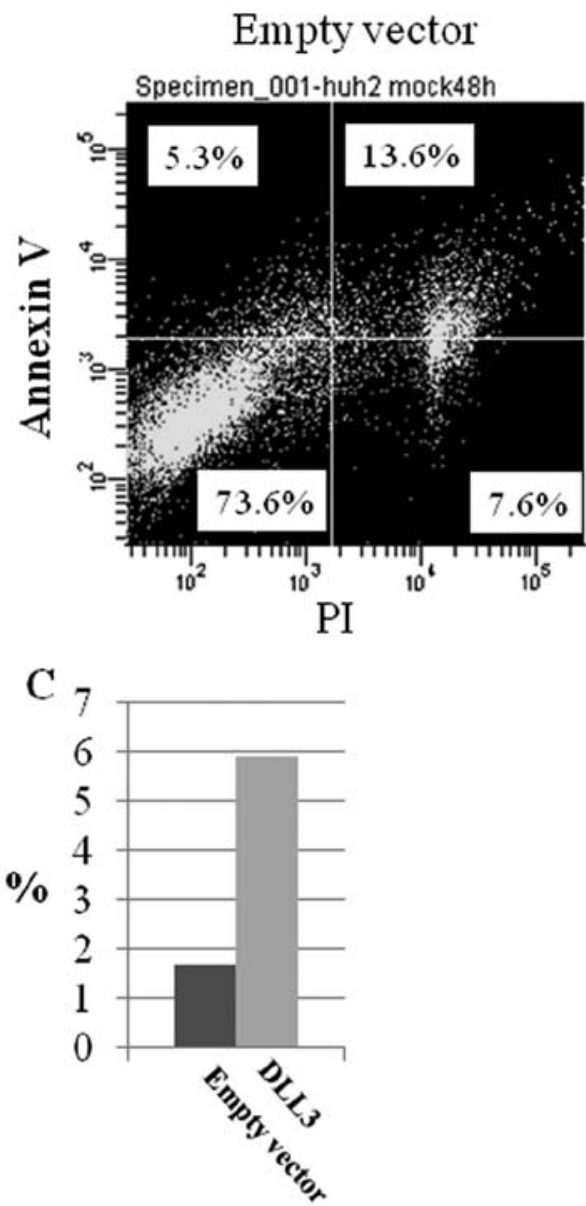

B

\section{DLL3}
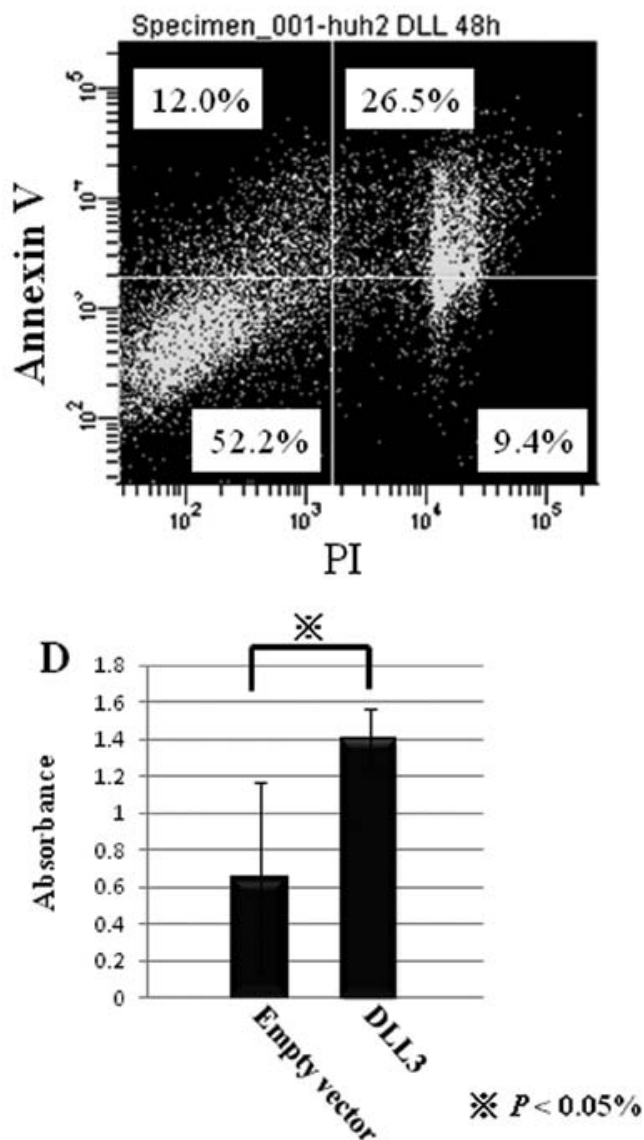

Figure 3. Induction of cell death by DLL3. Methylation-silenced HuH2 cells were transiently transfected with either (A) backbone vector or (B) DLL3 expression vector and cell death was detected by flow cytometry using PI and Annexin V staining. (C) Apoptotic cells were detected with the TUNEL method in HuH2 cells transfected with either backbone vector or DLL3 expression vector and numbers of TUNEL-positive cells were counted under microscopy. (D) Amount of single-stranded DNA was compared between control and DLL3-transfected cells by ELISA.

respectively (Fig. 3A and B). On the other hand, 35.9 and 38.5\% of DLL3-transfected cells were positive for PI and Annexin V, respectively. These results suggest that overexpression of DLL3 induced cell death in $\mathrm{HuH} 2$ cells chiefly via apoptosis.
Induction of apoptosis by DLL3 expression. In order to confirm the apoptotic effects of DLL3 on HuH2 cells, apoptotic cells were detected by the TUNEL method. As shown in Fig. 3C, the number of TUNEL-positive cells increased by transfection of 


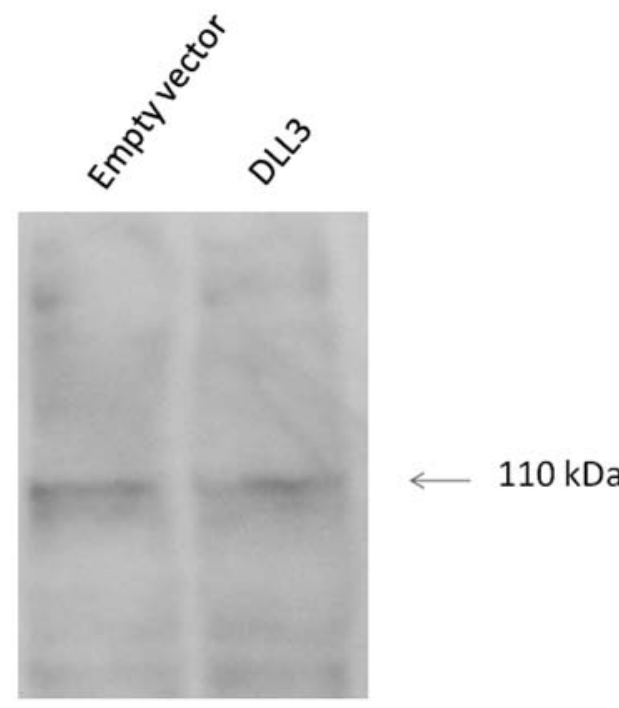

Figure 4. Notch activation by DLL3. Methylation-silenced HuH2 cells were transiently transfected with either DLL3 expression vector or backbone vector and activation of Notch1 was detected by western blot analysis.

DLL3. The percentage of TUNEL-positive cells in mock-transfected cells and DLL3-transfected cells was 1.68 and $5.93 \%$, respectively. Furthermore, the amount of single-stranded DNA was significantly increased by transfection of DLL3 in $\mathrm{HuH} 2$ cells (Fig. 3D). These data support the notion that restoration of DLL3 induces apoptosis in HuH2 cells in which DLL3 is silenced by DNA methylation.

Effects of DLL3 on Notchl activation. Notch1 is a transmembrane protein and the carboxy-terminal Notch1 fragment is released upon binding to a ligand. The resulting activated cytosolic fragment translocates to the nucleus, where it activates transcription. As shown in Fig. 4, western blot analysis showed no significant differences in cleaved Notch1 expression upon overexpression of DLL3.

\section{Discussion}

HCC develops as a result of aberrant genetic and epigenetic events, similarly to other cancers (1). Mutations in tumor suppressor genes, such as $p 53, \beta$-catenin and Axin, are detected in $20-30 \%$ of HCC samples $(24,25)$. The epigenetic pathway involves hypomethylation of the $\mathrm{HCC}$ genome causing genomic instability, hypermethylation of $\mathrm{CpG}$ islands in promoter sequences leading to inactivation of the genes, and histone modification affecting chromatin conformation. In HCC, aberrant promoter hypermethylation associated with gene silencing is observed in genes such as SOCS-1, SOCS-3, ASCL, p16 ${ }^{I N K 4 a}$, Ras association domain family $1 A$ (RASSF1A), placental glutathione S transferase P1 (GSTP1) and E-cadherin (8-10,26-29).

Yoshikawa et al (6) analyzed genomic NotI restriction sites in human HCC and found aberrantly methylated genes, including SOCS-1, SOCS-3, ASCL and DLL3, from multiple aberrant NotI sites. SOCS-1, known as JAB and SS-1, switches cytokine signaling 'off' by means of its direct interaction with Janus kinase (JAK). The authors demonstrated that restoration of SOCS-1 suppressed growth rate and anchorage-independent growth of cells in which $S O C S-1$ is methylation-silenced and JAK2 was constitutively activated (8). SOCS-3, which is methylation-silenced in $\mathrm{HCC}$, negatively regulates cell growth and cell migration by enhancing JAK/STAT and FAK signaling (9). The restoration of ASCL in methylation-silenced HCC cells induces growth suppression by the induction of apoptosis (10).

In this study, we found that DLL3 is also silenced in HCC cells by aberrant promoter methylation and that the restoration of DLL3 in methylation-silenced $\mathrm{HuH} 2$ cells leads to cell growth suppression by induction of apoptosis. We detected apoptosis by the TUNEL method and expression of Annexin V, an early marker for apoptosis. About 5.9\% of the DLL3-transfected cells were positive for TUNEL staining, whereas $38.5 \%$ of the transfected cells were positive for Annexin $\mathrm{V}$ expression. It is possible that methodological differences explain why the ratio of apoptotic cells differed between the two experiments; for detection of Annexin V expression, both adherent and floating cells were subjected to flow cytometry, whereas TUNEL staining was carried out using only adherent cells on the cover slip. In both experiments, apoptotic cells were detected at 3.5 and 2.0-fold higher levels when compared to mock-treated cells. Moreover, the amount of single-stranded DNA was significantly increased in DLL3-transfected cells, and this suggests apoptotic effects for DLL3 in HCC.

DLL3 is a member of the DSL ligands (Delta, Serrate and Lag2), which are type 1 cell surface proteins having multiple tandem epidermal growth factor (EGF) repeats in their extracellular domains. In addition, Delta and Serrate proteins contain a conserved cysteine-rich region known as the DSL domain in their extracellular portion. The DSL domain, flanking N-terminal domain, and the first two EGF repeats are required for binding to Notch $(30,31)$. DLL3 is the shortest among the three DLL ligands, with only six EGF-like repeats compared with the eight repeats identified in DLL1 and DLL4. The functions of DLL3 in Notch signaling have been complicated by conflicting reports.

Dunwoodie et al (14) reported that injection of DLL3 RNA into Xenopus oocytes is able to inhibit primary neuron formation, as observed in ectopic expression of constitutively active Notch1, suggesting that DLL3 is able to activate Notch signaling. However, Ladi et al reported that DLL3 does not bind or activate any of the known mammalian Notch receptors when presented in trans, although DLL3 inhibited ligandinduced Notch signaling when coexpressed with Notch at the cell surface in cis (15). In addition, Geffers et al recently reported that DLL3 does not activate Notch in D. melanogaster nor repress DLL1-mediated Notch activation in vivo. They also demonstrated that endogenous DLL3 predominantly resides in the Golgi apparatus and is virtually absent from the cell surface, whereas DLL1 is located on the cell surface (16). These results strongly suggest that DLL3 differs functionally from other DSL ligands.

Our western blot analysis demonstrated that overexpression of DLL3 does not increase the expression of cleaved Notch1 in $\mathrm{HuH} 2$ cells, thus suggesting that cell growth suppression is induced via a Notch-independent pathway. However, it is not clear how DLL3 induced apoptosis in HCC cells, its Golgi localization may be the key to understanding the novel function of DLL3, including cell growth suppression. In summary, we found that restoration of DLL3 expression induced apoptosis in $\mathrm{HuH} 2$ cells via a Notch1-independent pathway. 


\section{References}

1. Herath NI, Leggett BA and MacDonald GA: Review of genetic and epigenetic alterations in hepatocarcinogenesis. J Gastroenterol Hepatol 21: 15-21, 2006.

2. Yang B, Guo M, Herman JG and Clark DP: Aberrant promoter methylation profiles of tumor suppressor genes in hepatocellular carcinoma. Am J Pathol 163: 1101-1107, 2003.

3. Zhu JD: DNA methylation and hepatocellular carcinoma. J Hepatobiliary Pancreat Surg 13: 265-273, 2006.

4. Lee S, Lee HJ, Kim JH, Lee HS, Jang JJ and Kang GH: Aberrant $\mathrm{CpG}$ island hypermethylation along multistep hepatocarcinogenesis. Am J Pathol 163: 1371-1378, 2003.

5. Nagai H, Ponglikitmongkol M, Mita E, Ohmachi Y Yoshikawa H, Saeki R, Yumoto Y, Nakanishi T and Matsubara K: Aberration of genomic DNA in association with human hepatocellular carcinomas detected by 2-dimensional gel analysis. Cancer Res 54: 1545-1550, 1994.

6. Yoshikawa H, Monte DL, Nagai H, Wands JR, Matsubara K and Fujiyama A: Chromosomal assignment of human genomic NotI restriction fragments in a two-dimentional electrophoresis profile. Genomics 31: 28-35, 1996.

7. Yoshikawa H, Nagai H, Oh KS, Tamai S, Fujiyama A, Nakanishi T, Kajiyama G and Matsubara K: Chromosomal assignment of aberrant NotI restriction DNA fragments in primary hepatocellular carcinoma. Gene 197: 129-135, 1997.

8. Yoshikawa H, Matsubara K, Qian GS, Jackson P, Groopman JD, Manning JE, Harris C and Herman JG: SOCS-1, a negative regulator of the JAK/STAT pathway, is silenced by methylation in human hepatocellular carcinoma and shows growth-suppression activity. Nat Genet 28: 29-35, 2001.

9. Niwa Y, Kanda H, Shikauchi Y, Saiura A, Matsubara K, Kitagawa T, Yamamoto J, Kubo $\mathrm{T}$ and Yoshikawa $\mathrm{H}$ : Methylation silencing of SOCS-3 promotes cell growth and migration by enhancing JAK/STS and FAK signaling in human hepatocellular carcinoma. Oncogene 24: 6406-6417, 2005.

10. Kubo T, Yamamoto J, Shikauchi Y, Niwa Y, Matsubara K and Yoshikawa H: Apoptotic speck protein-like, a highly homologous protein to apoptotic speck protein in the pyrin domain, is silenced by DNA methylation and induces apoptosis in human hepatocellular carcinoma. Cancer Res 64: 5172-5177, 2004.

11. D'Souza B, Miyamoto A and Weinmaster G: The many facets of Notch ligands. Oncogene 27: 5148-5167, 2008.

12. Bray SJ: Notch signaling: a simple pathway becomes complex. Nat Rev Mol Cell Biol 7: 678-689, 2006.

13. Fiuza UM and Arias AM: Cell and molecular biology of Notch. J Endocrinol 194: 459-474, 2007.

14. Dunwoodie SL, Henrique D, Harrison SM and Beddington RSP: Mouse Dll3: a novel divergent Delta gene which may complement the function of other Delta homologues during early pattern formation in the mouse. Development 124: 3065-3076, 1997.

15. Ladi E, Nichols JT, Ge W, Miyamoto A, Yao C, Yang LT, Boulter J, Sun YE, Kintner C and Weinmaster G: The divergent DSL ligand Dll3 does not activate Notch signaling but cell autonomously attenuates signaling induced by other DSL ligands. J Cell Biol 170: 983-992, 2005.

16. Geffers I, Serth K, Chapman G, Jaekel R, Schuster-Gossler K Cardes R, Sparrow DB, Kremmer E, Dunwoodie S, Klein T and Gossler A: Divergent functions and distinct localization of the Notch ligands DLL1 and DLL3 in vivo. J Cell Biol 30: 465-476, 2007.

17. Conlon RA, Reaume AG and Rossant J: Notch1 is required for the coordinate segmentation of somites. Development 121 : 1633-1645, 1995.
18. Kusumi K, Sun ES, Kerrebrock AW, Bronson RT, Chi DC and Bulotsky MS: The mouse pudgy mutation disrupts Delta homologue Dll3 and initiation of early somite boundaries. Nat Genet 19: 274-278, 1998.

19. Dunwoodie SL, Clements M, Sparrow DB, Sa X, Conlon RA and Beddington RS: Axial skeletal defects caused by mutation in the spondylocostal dysplasia/pudgy gene D113 are associated with disruption of the segmentation clock within the presomitic mesoderm. Development 129: 1795-1806, 2002.

20. Bulman MP, Kusumi K, Frayling TM, McKeown C, Garrette C, Lander ES, Krumlauf R, Hattersley AT, Ellard S and Turnpenny PD: Mutations in the human delta homologues, DLL3, cause axial skeletal defects in spondylocostal dysostosis. Nat Genet 24: 438-441, 2000.

21. Sparrow DB, Clements M, Withington SL, Scott AN, Novotny J, Sillence D, Kusumi K, Beddington RS and Dunwoodie SL: Diverse requirements for $\mathrm{N}$ signaling in mammals. Int $\mathrm{J}$ Dev Biol 46: 365-374, 2002.

22. Turnpenny PD, Whittock N, Duncan J, Dunwoodie S, Kusumi K and Ellard S: Novel mutations in DLL3, a somitogenesis gene encoding a ligand for the $\mathrm{N}$ signaling pathway, cause a consistent pattern of abnormal vertebral segmentation in spondylocostal dysostosis. J Med Genet 40: 333-339, 2003.

23. Herman JG, Graff JR, Myohanen S, Nelkin BD and Baylin SB: Methylation-specific PCR: a novel PCR assay for methylation status of CpG islands. Proc Natl Acad Sci USA 93: 9821-9826, 1996.

24. Lunn RM, Zhang YJ, Wang LY, Chen CJ, Lee PH, Lee CS, Tsai WY and Santella RM: p53 mutations, chronic hepatitis B virus infection, and aflatoxin exposure in hepatocellular carcinoma in Taiwan. Cancer Res 57: 3471-3477, 1997.

25. De la Costa A, Romagnolo B, Billuart P, Renard CA, Buendia MA, Soubrane O, Fabre M, Chelly J, Beldjord C, Kahn A and Perret C: Somatic mutations of the beta-catenin gene are frequent in mouse and human hepatocellular carcinomas. Proc Natl Acad Sci USA 95: 8847-8851, 1998.

26. Matsuda Y, Ichida T, Matsuzawa J, Sugimura K and Asakura H: p16(INK4) is inactivated by extensive $\mathrm{CpG}$ methylation in human hepatocellular carcinoma. Gastroenterology 116: 394-400, 1999.

27. Schagdarsurengin U, Wikens L, Steinemann D, Flemming $P$, Kreipe HH, Pfeifer GP, Schlegelberger B and Dammann R: Frequent epigenetic inactivation of the RASSF1A gene in hepatocellular carcinoma. Oncogene 22: 1866-1871, 2003.

28. Tchou JC, Lin X, Freije D, Isaacs WB, Brooks JD, Rashid A, De Marzo AM, Kanai Y, Hirohashi S and Nelson WG: GSTP1 $\mathrm{CpG}$ island DNA hypermethylation in hepatocellular carcinomas. Int J Oncol 16: 663-676, 2000.

29. Liu J, Lian Z, Han S, Waye MMY, Wang H, Wu MC, Wu K, Ding J, Arbuthnot P, Kew M, Fan D and Feitelson MA: Downregulation of E-cadherin by hepatitis $\mathrm{B}$ virus $\mathrm{X}$ antigen in hepatocellular carcinoma. Oncogene 25: 1008-1017, 2006.

30. Parks AL, Stout JR, Shepard SB, Klueg KM, Dos Santos AA, Parody TR, Voskova M and Muskavitch AT: Structure-function analysis of delta trafficking, receptor binding and signaling in Drosophila. Genetics 174: 1947-1961, 2006.

31. Shimizu K, Chiba S, Kumano K, Hosoya N, Takahashi T, Kanda Y, HamadaY, Yazaki Y and Hirai H: Mouse Jagged1 physically interacts with Notch2 and other Notch receptors. Assessment by quantitative methods. J Biol Chem 274: 32961-32969, 1999. 